\title{
SURVEY 2016: TEKNISK RAPPORT
}

\author{
Magnus Hagevi, Linnéuniversitet \\ E-post I magnus.hagevi@1nu.se
}

Surveyinstitutet vid Linnéuniversitetet har genomfört en frågeundersökning år 2016. Frågeundersökningen kallas för Survey 2016. Survey 2016 var speciellt inriktad på att undersöka medborgarnas inställning till politiska partier, maktmissbruk och korruption, musiksmak och festival, entreprenörskap samt individens religiositet. Denna artikel är en teknisk rapport av frågeundersökningen Survey 2016. Rapporten behandlar frågeformulär, fältarbetets uppläggning, population, urval och svarsfrekvens samt bortfallsanalys. Survey 2016 är den femte nationella frågeundersökningen som Surveyinstitutet har genomfört. De två tidigare är Survey 2009, Survey 2010, Survey 2012 och Survey 2014 (för teknisk rapport om dessa, se Hagevi 2010, 2011, 2014, 2015). Survey 2016 har genomgått etikprövning och godkänts av Regionala etikprövningsnämnden i Linköping.

\section{Frågeformulär}

Till personerna i urvalet skickades ett frågeformulär på 12 sidor. De frågor som ingick i frågeformuläret behandlade värden och ideologi, politiskt deltagande, röstning och partipreferenser, politiska åsikter och religiositet. Till dessa frågor tillkom så kallade bakgrundsfrågor som tog upp uppgifter som svarspersonen rörande kön, födelseår, syskon och föräldrar i uppväxtfamiljen, klass och yrke, utbildning, etnisk bakgrund, inkomster och nuvarande familjeförhållanden. Hela frågeformuläret redovisas i bilaga $1 \mathrm{i}$ form av en kodbok. 
I tabell 1 redovisas dispositionen av innehållet i Survey 2016:s frågeformulär.

Tabell 1. Innehåll i Survey 2016

\begin{tabular}{ll}
\hline Frågenummer & Ämnesområde \\
\hline $1-10$ & Värderingar \\
$11-15$ & Maktmissbruk \\
16 & Politiska åsikter \\
$17-31$ & Politiska partier \\
$32-38$ & Religiositet \\
$39-40$ & Musiksmak \\
$42-43$ & Musikfestival \\
$44-49$ & Entreprenörskap \\
$50-68$ & Bakgrund: uppväxt, utbildning, yrke och inkomst, härkomst, familjeförhållanden \\
\hline
\end{tabular}

Frågeformuläret har utarbetats i samarbete mellan Surveyinstitutet och de deltagande forskningsprojekten. För att besvara frågorna kryssar svarspersonen i en ruta som indikerar det färdigformulerade svar som svarspersonen anser är lämpligast. Det finns ett fåtal möjligheter att komplettera med mycket kortfattade öppna svar.

\section{Frågeundersökningens genomförande}

Fältarbetet för Survey 2016 genomfördes av TNS-Sifo (där Caroline Theorell ledde fältarbetet) under några månader i slutet av 2016. Den första kontakten med svarspersonerna skedde i mitten av september 2016 och sista svaret mottogs i mitten av december 2016. Fältarbetet inleddes med att personerna i urvalet fick ett vykort med posten (vykortet skickade måndag 19 september). Syftet med vykortet var att informera personerna i urvalet att de blivit utvalda att ingå i Survey 2016. Fredag 27 september skickades frågeformuläret ut med post. Med frågeformuläret sändes också uppgifter som innebar att personerna i urvalet kunde svara på enkäten via Internet, en så kallad webbenkät.

Därefter vidtar en omfattande aktivitet för att få så många som möjligt av personerna i urvalet att svara på enkäten. Ett "tack- och påminnelsekort" skickade ut till personerna i urvalet måndagen 4 oktober till samtliga personer i urvalet. Ett andra utskick med ännu ett enkätformulär sändes ut måndagen 11 oktober till de i urvalet som ännu inte besvarat Survey 2016. Även nu fick personerna i urvalet information om möjligheten att svara via webbenkät. Det tredje utskicket, även det med enkätformulär på Survey 2016 och med instruktion om möjligheten att svara via webbenkät, skickades till de kvarvarande i urvalet som inte svarat måndagen 4 november, vilket följdes upp med ett påminnelsekort tisdagen 22 november. Sista svaret noterades tisdag 13 december 2016 varefter datainsamlingen avslutades.

För att öka svarsfrekvensen erbjöds samtliga personer i urvalet som besvarade enkäten trisslotter. Efter fältperioden avslutats sändes tackbrev och trisslott till alla svarande. 


\section{Population, urval och svarsfrekvens}

Frågeundersökningen Survey 2016 genomförs i form av en postenkät till ett obundet sannolikhetsurval. I urvalsramen ingår samtliga boende i Sverige i åldrarna 18 till 85 år. Inte enbart svenska medborgare ingår i undersökningen, utan även utländska medborgare. Urvalet består av 3000 personer, vilket efter att ha beaktat naturligt bortfall återstår 2958 personer i det så kallade nettourvalet. Andelen nettosvarande beräknas genom att beakta de frågeformulär som inte nått fram till svarspersonen (bland annat på grund av att de avlidit, har sjukdom som förhindrar svar, flyttat utan angiven svensk adress eller liknande skäl), så kallat naturligt bortfall. För de personer som ingår i urvalet är deltagande i undersökningen frivilligt.

När fältarbetet avslutades var andelen svarande 43,0 procent av hela urvalet, vilket var 1290 svar (se tabell 2). Om andelen svarande beräknas på nettourval är svarsandelen 43,6 procent.

Tabell 2. Svar och bortfall i Survey 2016.

\begin{tabular}{lr}
\hline Bruttourval & 3000 \\
Naturligt bortfall & 42 \\
Nettourval & 2958 \\
Antal svarsvägrare & 1668 \\
Antal svarande & 1290 \\
Andel nettosvar (i procent) & 43,6 \\
Andel svarande (i procent) & 43,0 \\
\hline
\end{tabular}

I kategorin svarsvägrare ingår de personer som på eget initiativ meddelat att de ej vill delta $\mathrm{i}$ undersökningen och de som inte deltagit i undersökningen utan att meddela detta (ej anträffade).

I figur 1 redovisas den kumulativa nivån av de besvarade enkäterna under fältarbetet.

Enligt sammanställningen i figur 1 har de flesta svarspersoner sänt in enkäten tidigt under fältperioden. Av den totala andelen besvarade enkäter i Survey 2016 hade 66 procent kommit in redan de första två veckorna i oktober. Sista oktober hade ytterligare 23 procentenheter besvarat Survey 2016, det vill säga 89 procent av det totala antalet svarande. De sista 11 procenten svar inkom under november och första halvan av december.

Personerna i urvalet hade möjlighet att besvara enkäten med post (postal enkät) eller Internet (webbenkät). I figur 2 presenteras inflödet av postal enkät respektive webbenkät i form av antal svar.

Av figur 2 framgår att de flesta svarande använt postal enkät. Av samtliga svarande brukade 75,2 procent alternativet att besvara enkäten via post och 24,8 procent använde sig av webbenkäten. Bland dem som svarade med webbenkät var det aningen vanligare att svara tidigt (61,4 procent av användarna av webbenkät hade besvarat Survey 2016 de första två veckorna $\mathrm{i}$ oktober än vad som var fallet bland personer som besvarat via enkätformuläret och skickat tillbaka det med post (67,8 procent av användarna av postal enkät hade besvarat Survey 2016 de 
första två veckorna i oktober). Jämfört med tidigare undersökningarna har denna skillnad minskat betydligt, då det i tidigare undersökningar varit vanligare att svarspersonerna som använde webbenkät i större utsträckning skickade in sina enkätformulär tidigt. En möjlig förklaring till denna förändring skulle kunna ha varit att sista påminnelsen utgjordes av ett vykort med instruktioner att besvara Survey 2016 genom Webbenkäten. Påminnelsen innehöll information om hur svarspersonen kunde beställa ett enkätformulär på papper, men någon pappersenkät bifogades inte. Trots detta utgjordes 62 procent av dem som efter detta utskick besvarade Survey 2016 av personer som använde postenkäten, medan endast 38 procent begagnade webbenkäten.

Figur 1. Kumulativt inflöde av samtliga enkäter i Survey 2016 (procent av samtliga svar).

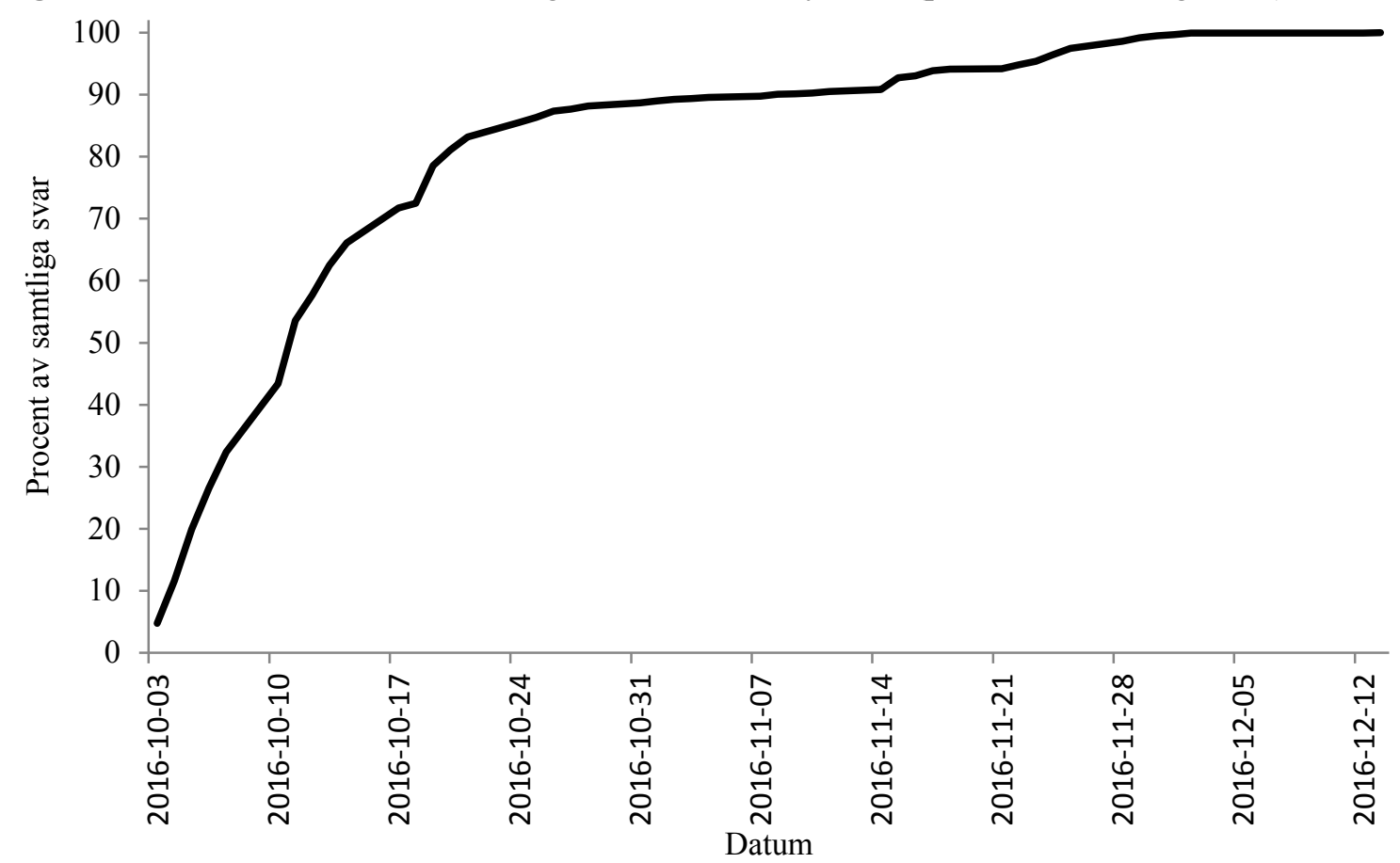


Figur 2. Kumulativt inflöde av postala- och webbenkäter i Survey 2016 (antal besvarande enkäter).

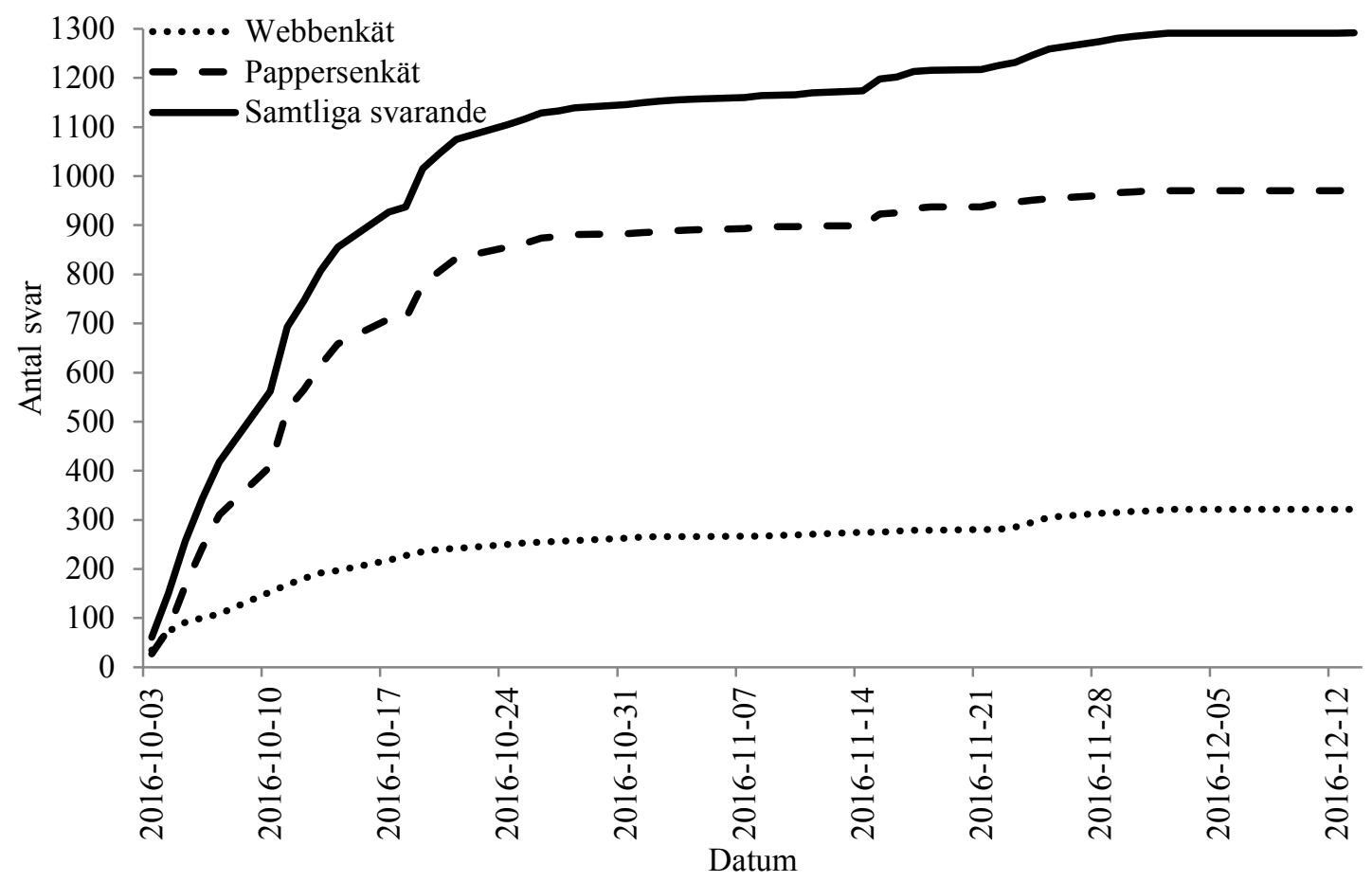

Inflödet av frågeformulär påverkades också av de olika påminnelserna och utskicken som genomfördes under fältarbetet. Effekterna av respektive moment under fältarbetet är mer märkbara om inflödet av enkäter studeras dagligen, något som redovisas i figur 3. Beräknad tid för när personer i urvalet mottaget en påminnelse är markerad med romber utmed linjen som markerar antalet svar. 
Figur 3. Veckovis inflöde av samtliga enkäter i Survey 2016 (antal besvarade enkäter).

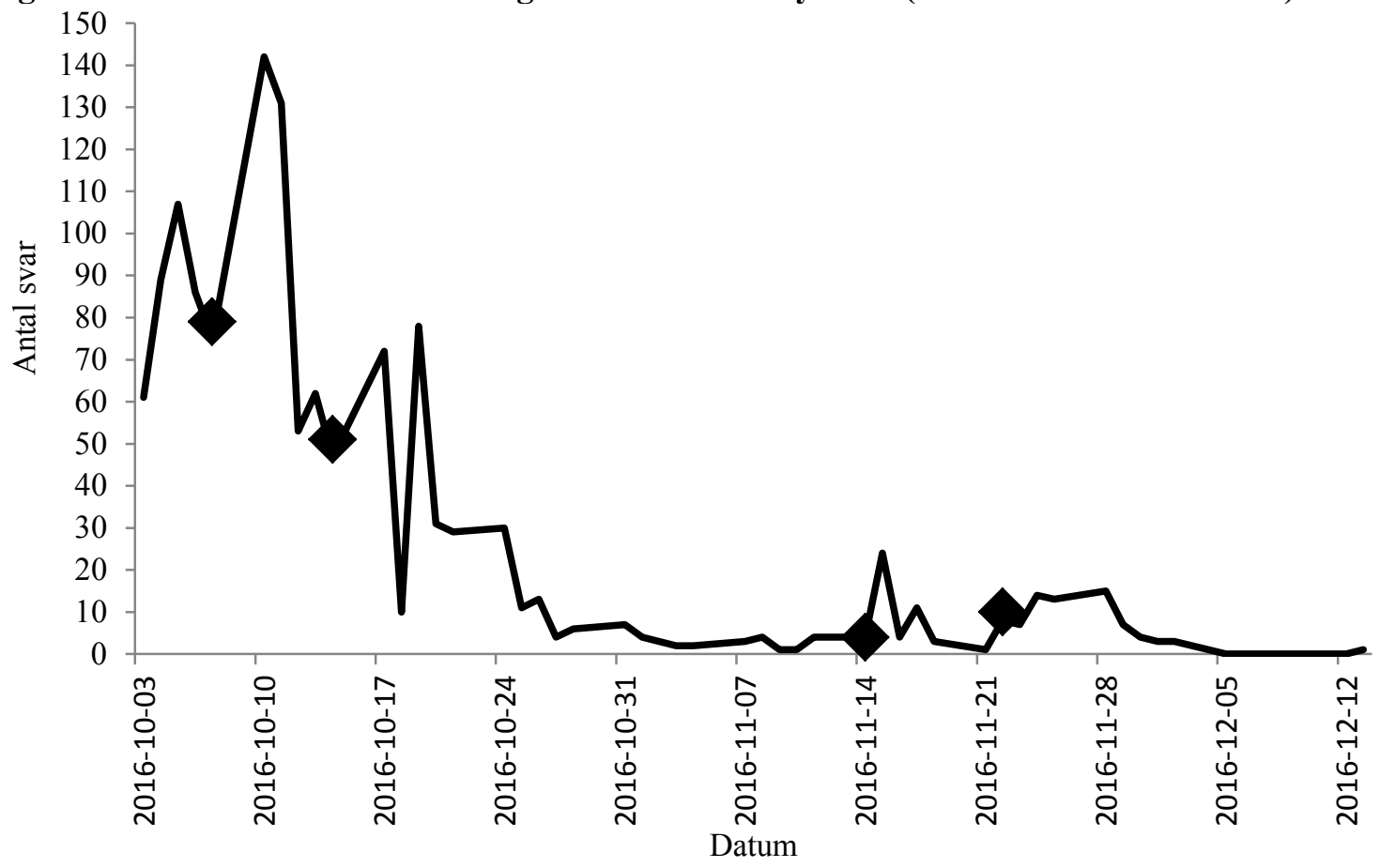

Av figur 3 framgår återigen att de flesta personer som besvarat Survey 2016 har gjort detta tidigt under fältarbetsperioden. Jämfört med flera tidigare undersökningar (Hagevi 2010, 2011, 2014) var antalet svarande färre under fältperiodens första vecka, medan det färre antalet svarande under fältperiodens tidiga fas känns igen från Survey 2014 (Hagevi 2015). Efter det att påminnelser skickats till de svarande har fler svar skickats in, dock med en avtagande verkan allt eftersom undersökningen fortgår. Undantaget sista påminnelsen (där inget pappersformulär skickades ut) är det framförallt postala enkäter som svarspersonerna använder efter påminnelser.

\section{Bortfallsanalys: kön, ålder och region}

Bortfall sker inte slumpvis. Beroende på personliga egenskaper skiftar benägenheten att besvara enkäter. Detta kan påverka undersökningens representativitet. Personer med gemensamma egenskaper kan till exempel ha liknande åsikter som skiljer sig från andra personer med andra egenskaper. Om en grupp med likartade och avvikande åsikter dessutom tenderar att i större utsträckning inte besvara enkäten minskar undersökningens representativitet (Hagevi och Viscovi 2016). Ett sätt att kontrollera om bortfallet kan påverka representativiteten är att undersöka i vad mån andelen svarande skiftar beroende på olika egenskaper hos personerna $\mathrm{i}$ urvalet. I Survey 2016 är det möjligt att genomföra en bortfallsanalys utifrån kön, ålder och region (se tabell 3). 
Tabell 3. Andel svarande av nettourvalet (2882 personer) efter kön, ålder och region (procent).

\begin{tabular}{|c|c|c|}
\hline Kön & $\begin{array}{l}\text { Kvinnor } \\
\text { Män }\end{array}$ & $\begin{array}{l}58 \\
42\end{array}$ \\
\hline Ålder & $\begin{array}{l}18-25 \stackrel{\circ}{a r} \\
26-30 \stackrel{\circ}{ } \\
31-40 \stackrel{\circ}{\circ} \\
41-50 \stackrel{\circ}{ } \\
51-60 \stackrel{\circ}{a} \\
61-65 \stackrel{\circ}{\circ} \\
66-75 \stackrel{\circ}{ } \\
76-85 \stackrel{\circ}{\circ}\end{array}$ & $\begin{array}{l}29 \\
26 \\
39 \\
38 \\
47 \\
42 \\
62 \\
48\end{array}$ \\
\hline Region & $\begin{array}{l}\text { Stockholms län } \\
\text { Östra Mellansverige } \\
\text { Småland med öarna } \\
\text { Sydsverige } \\
\text { Västsverige } \\
\text { Norra Mellansverige } \\
\text { Mellersta Norrland } \\
\text { Övre Norrland }\end{array}$ & $\begin{array}{l}40 \\
42 \\
44 \\
41 \\
49 \\
41 \\
46 \\
41\end{array}$ \\
\hline
\end{tabular}

Svarsandelen varierar något mellan olika regioner. Flest andel svar kommer från Västra Götaland och Mellersta Norrland. För övriga regioner är variationen i andelen svarande relativt liten. Det är en större andel av kvinnorna i urvalet som besvarat enkäten än vad det är män. Äldre besvarar oftare Survey 2016 än yngre. Tendensen att svarsandelen ökar bland personer som är över 50 år känns igen från tidigare mätningar. I ålderkategorin 66-75 år har speciellt många besvarat undersökningen. Andelen svarande bland personer som är 18-30 år är dock mycket låg.

\section{Svarspersonernas representativitet}

Avsikten med Survey 2016 är att de svarande skall vara representativa med svenska befolkningen mellan 18 och 85 år. I den mån det finns avvikelser mellan kända egenskaper i den svenska befolkningen och svarspersonerna - de personer i urvalet som besvarat och skickat tillbaka frågeformulären - i Survey 2016 visar det på minskad representativitet mellan population och svarspersonerna i urvalet. I tabell 4 redovisas svarspersonernas sammansättning beträffande kön, ålder, region och medborgarskap. Denna fördelning i urvalet jämförs med sammansättningen i den svenska befolkningen. Data för svenska befolkningen i åldersintervallet 18-85 år har hämtats från Statistiska centralbyrån (SCB). 
Tabell 4. Urval- och svarspersonernas fördelning angående kön, ålder, region och medborgarskap i jämförelse med svenska befolkningen (procent).

\begin{tabular}{|c|c|c|c|c|c|c|}
\hline & & $\begin{array}{l}\text { Urval i } \\
\text { Survey } \\
2016\end{array}$ & $\begin{array}{c}\text { Svarande i } \\
\text { Survey } \\
2016\end{array}$ & $\begin{array}{l}\text { Svenska } \\
\text { befolk- } \\
\text { ningen }\end{array}$ & $\begin{array}{c}\text { Differens } \\
\text { urval- } \\
\text { befolkn. }\end{array}$ & $\begin{array}{c}\text { Differens } \\
\text { svarande- } \\
\text { befolkn. }\end{array}$ \\
\hline \multirow[t]{2}{*}{ Kön } & Kvinnor & 50 & 53 & 50 & 0 & +3 \\
\hline & Män & 50 & 47 & 50 & 0 & -3 \\
\hline \multirow[t]{8}{*}{ Ålder } & $18-25$ ar & 10 & 6 & 14 & -4 & -8 \\
\hline & $26-30 \mathrm{a} r$ & 8 & 6 & 8 & 0 & -2 \\
\hline & $31-40 \stackrel{\circ}{a} r$ & 16 & 14 & 16 & 0 & -2 \\
\hline & $41-50 \mathrm{a} r$ & 19 & 17 & 18 & +1 & -1 \\
\hline & $51-60 \stackrel{a}{a}$ & 16 & 17 & 16 & 0 & +1 \\
\hline & $61-65 \stackrel{a r}{\mathrm{r}}$ & 8 & 10 & 8 & 0 & +2 \\
\hline & $66-75 \stackrel{a r}{r}$ & 15 & 21 & 14 & +1 & +7 \\
\hline & $76-85 \stackrel{\circ}{a} r$ & 8 & 9 & 7 & +1 & +2 \\
\hline \multirow[t]{8}{*}{ Region } & Stockholms län & 23 & 22 & 22 & +1 & 0 \\
\hline & Östra Mellansverige & 16 & 17 & 17 & -1 & 0 \\
\hline & Småland med öarna & 8 & 9 & 8 & 0 & +1 \\
\hline & Sydsverige & 14 & 14 & 15 & -1 & -1 \\
\hline & Västsverige & 19 & 19 & 20 & -1 & -1 \\
\hline & Norra Mellansverige & 9 & 8 & 9 & 0 & -1 \\
\hline & Mellersta Norrland & 5 & 5 & 4 & +1 & +1 \\
\hline & Övre Norrland & 6 & 6 & 5 & +1 & +1 \\
\hline
\end{tabular}

Kommentar: På grund av avrundning till heltal summeras svenska befolkningens fördelning på ålder och regioner inte till 100 procent.

De regionala skillnaderna som finns mellan svarspersonerna i Survey 2016 och svenska befolkningen är små. Jämfört med tidigare undersökningar från Surveyinstitutet (Hagevi 2010, 2011, 2014) är dock representativiteten för kön och delvis för ålder sämre. Kvinnor är något överrepresenterade och män underrepresenterade bland de svarande i Survey 2016. I den yngsta åldersgruppen 18-25 år är andelen av de svarande mindre än i svenska befolkningen medan i åldersgruppen 66-75 år är andelen av de svarande större än i svenska befolkningen. Orsak till den låga andelen svarande i den yngsta ålderskategorin är del en lägre svarsfrekvens än andra åldersgrupper, dels att urvalet underskattat andelen personer $\mathrm{i}$ ålder 18-25 år. I övriga åldersgrupper är skillnaderna små. Förutom dessa åldersgrupper och till viss del kön visar resultatet på att frågeundersökningen Survey 2016 har god representativitet.

Problem med sviktande svarsandelar som har samband med olika demografiska faktorer (bland annat kön, ålder och region) har undersökts av Elias Markstedt (2012). Huvudresultatet visar att minskad svarsandel endast marginellt förändrar svarsfördelningen på enkätfrågor av den typ som används i Survey 2016.

Den sannolikt mest omfattande skevheten som blir resultatet av bortfallet analyseras dock inte i tabell 4. Troligtvis återfinns personer med lågt politiskt intresse i större utsträckning i bortfallet än personer som är mer intresserade av politik. Anledningen till ett sådant bortfall är att Survey 2016 till stor del är inriktad på politiska frågor, vilket främst bör attrahera politisk intresserade 
att besvara undersökningen. I frågeundersökningar som tidigare genomförts av Surveyinstitutet har det dock funnits vissa möjligheter att undersöka effekten av bortfallet som har sitt ursprung i lågt politiskt intresse (Hagevi 2011). Survey 2010 genomfördes strax efter riksdagsvalet detta år. Största noterade skevheten i Survey 2010 rör en politisk aktivitet: deltagande i riksdagsvalet 2010. Av de svarande som är röstberättigade uppger 94 procent att de röstade i riksdagsvalet, vilket är mer än det officiella valdeltagandet på 85 procent röstande, en skillnad på 9 procentenheter. Bland de svarande i Survey 2016 var valdeltagandet i riksdagsvalet 97 procent, vilket kan jämföras med det officiella valdeltagandet på 86 procent röstande.

Det kan finnas flera orsaker till överrepresentationen av andelen röstande i Survey 2010 och 2014, en av dem torde vara skevt bortfall. ${ }^{1}$ Eftersom politiskt intresserade också röstar i större utsträckning än personer som är mer ointresserade av politik är det möjligt att överrepresentationen av röstande är ett resultat av att det är vanligare att politiskt intresserade personer besvarat Survey 2010 och 2014 än vad det är att relativt politiskt ointresserade personer gjort det samma. I Survey 2010 framgår det att andelen som själva uppfattar sig vara mycket eller ganska mycket intresserade av politik är större bland dem som också säger att de röstade i riksdagsvalet (61 procent, $\mathrm{n}=1331$ ) än bland dem som besvarat Survey 2010 utan att ha röstat i riksdagsvalet trots att de hade rösträtt ( 30 procent, $n=81$ ). Eftersom politiskt intresserade också röstar i större utsträckning än personer som är mindre intresserade av politik är det möjligt att andelen personer i urvalet som besvarade Survey 2010 och 2014 är större bland dem röstande i riksdagsvalet än dem som inte deltog i detta val. Valdeltagande blir därför högre $\mathrm{i}$ Survey 2010 jämfört med riksdagsvalet. Det är också värt att notera att med ett större bortfall i Survey 2016 har också överrepresentationen i valdeltagande ökat jämfört med Survey 2010. Det finns således risk för att politisk aktivitet och poliskt deltagande är särskilt överskattat i Survey 2016. Detta ger implikationer för tolkningen av nivåskattningar i undersökningen. När politisk aktivitet undersöks i Survey 2016 är det troligt att den politiskt aktiva andelen är överrepresenterad i jämförelse med motsvarande andel i den svenska befolkningen. I exemplet med röstande i riksdagsvalet 2014 är överskattningen ungefär 13 procent $(86 \cdot 1,13 \approx 97)$.

\section{Sammanfattning}

Survey 2016 är en omfattande undersökning som beaktar en bred spektra av politiska frågor och förhållanden i det svenska samhället. Därmed finns det goda möjligheter att genomföra flera intressanta analyser av svenska befolkningen med Survey 2016. Analyser av datamaterialet bör dock beakta en viss sannolik överskattning i nivån av politiskt intresse och deltagande, att unga är underrepresenterade och personer i ålder 66-75 år överrepresenterade samt att kvinnor är något överrepresenterade, män något underrepresenterade. Om detta beaktas är de data som samlats in genom Survey 2016 är en bas för att genomföra analyser av befolkningen i det svenska samhället. 


\section{Noter}

${ }^{1}$ Det finns även andra möjliga förklaringar till att valdeltagandet i Survey 2010 och 2014 skiljer sig från den faktiska andelen röstande. Svarspersonerna kan dessutom ha glömt om de röstat eller inte. Det är också möjligt att svarspersonerna uppfattar att det inte är etiskt försvarbart att inte rösta, varför de kan uppge att de röstat även om så inte varit fallet.

\section{Referenser}

Hagevi, Magnus (2010): "Survey 2009: teknisk rapport" i Avstamp: Svenska folkets värden och syn på brännande samhällsfrågor, red Magnus Hagevi. Växjö: Linnaeus University Press.

Hagevi, Magnus (2011): "Survey 2010: teknisk rapport" i Den svenska väljaren, red Magnus Hagevi. Umeå: Boréa förlag.

Hagevi, Magnus (2014): "Survey 2012: teknisk rapport", Surveyjournalen, 1(1): 59-67.

Hagevi, Magnus (2015): "Survey 2014: teknisk rapport", Surveyjournalen, 2(1-2): 125-132.

Hagevi, Magnus och Dino Viscovi (2016): Enkäter: Att formulera frågor och svar. Lund:

Studentlitteratur.

Markstedt, Elias (2012): Representativitet och viktning: Riks-SOM som spegel av det svenska samhället 1986-2011. SOM-rapport nr 2012:30. Göteborg: SOM-institutet, Göteborgs universitet. 